研

究

\title{
$\mathrm{BaTiO}_{3}$ セラミックスのマイクロ波焼成とその焼結体の電気的特性一液相の影響
}

\author{
西村ゆつき，安岡 正喜，長岡 孝明，杵鞭 義明，渡利 広司 \\ 産業技術総合研究所，４ 463-8560 名古屋市守山区下志段味穴ヶ洞 2266-98
}

\section{Microwave Sintering and Dielectric Properties of $\mathrm{BaTiO}_{3}$ Ceramics -Effect of liquid phase}

\author{
Yutsuki Nishimura, Masaki Yasuoka, Takaaki Nagaoka, Yoshiaki Kinemuchi and Koji Watari \\ National Institute of Advanced Industrial Science and Technology (AIST), Anagahora 2266-98, Shimoshidami, Moriyama-ku, Nagoya \\ 463-8560, Japan.
}

Received April 19, 2006

\begin{abstract}
SYNOPSIS
Effects of liquid phase on microwave sintering with a frequency of $2.45 \mathrm{GHz}$ of $\mathrm{BaTiO}_{3}$ ceramics were investigated. The additives to form the liquid were $\mathrm{BaCO}_{3}, \mathrm{H}_{3} \mathrm{BO}_{3}$ and $\mathrm{BaB}_{2} \mathrm{O}_{4}$. Addition of the liquid phase in microwave sintering promotes densification of $\mathrm{BaTiO}_{3}$ ceramics significantly, and densified ceramics were obtained by lower applied power and shorter processing time. Furthermore, electric resistivity of dense ceramics with $\mathrm{BaCO}_{3}+2 \mathrm{H}_{3} \mathrm{BO}_{3}$ addition was different by sintering techniques, and a sample obtained by microwave sintering showed the dielectric, while one obtained by conventional sintering showed the semiconducting properties. Such different result is considered to be relating to presence of liquid phase with strong microwave absorption.
\end{abstract}

KEY WORDS

microwave processing, sintering, $\mathrm{BaTiO}_{3}$, liquid phase sintering, dielectric property

\section{1 緒訔}

セラミックスの焼成プロセスは大量のエネルギーを消費す ることから, 省エネルギープロセスの開発が強く求められて いる. 省エネルギープロセスとしてこれまでいくつかの方法 が提案されており，マイクロ波をエネルギ一源とした焼成は 有効な焼成法の一つである，マイクロ波による焼成は，従来 の抵抗体の加熱による外部からの熱伝導によるものではなく 物質自身がマイクロ波を吸収し発熱することを利用したもの である.この特長を利用して，マイクロ波焼成は従来の方法 に比べて低温かつ短時間で緻密な焼結体が得られたという報 告が多くある ${ }^{1-5)}$. 一方, セラミックスの焼結プロセスの一つ である液相焼結では, 温度上昇に伴う液相の生成により粒子 間に生じた毛管力による粒子の再配列之, 液相を介した物質 移動によって拡散が促進されることにより，低温で緻密な焼 結体を得ることができる方法である. 照射波数(周波数)領域 の誘電損失に比例して加熱されるマイクロ波の特徵から，こ の値の異なる液相成分を選択することで生じたマイクロ波吸 収量の差に起因した特異な焼結挙動なども考えられる. 従つ て，マイクロ波焼成と液相焼結とを同時に利用することに
よってマイクロ波焼成の特長をより活かした低温焼成が期待 できる。

一般に, $\mathrm{BaTiO}_{3}$ (チタン酸バリウム)セラミックスは代表的 な誘電体材料であり, 本来は絶縁体であるが, $\mathrm{La}$ や $\mathrm{Nb}$ などの 3 価や 5 価の元素を微量添加することにより, 半導体化する ことが知られている. また, 還元雾囲気の焼成においても同 様に電気特性へ影響を及ぼすことが知られている.このように $\mathrm{BaTiO}_{3}$ セラミックスの焼成においては, 焼結助剂の添加や焼 成条件が $\mathrm{BaTiO}_{3}$ の特性に敏感に影響を及ぼすとされている.

本研究では, 低エネルギーで $\mathrm{BaTiO}_{3}$ セラミックスを焼結す るためにマイクロ波焼成と液相焼結を組み合わせた。液相成 分には $\mathrm{BaTiO}_{3}$ の焼結温度以下の $942^{\circ} \mathrm{C}$ で液相を生成し, かつ $\mathrm{BaTiO}_{3}$ と相互に影響を与えない物質である $\mathrm{BaB}_{2} \mathrm{O}_{4}{ }^{6}$ をを選択し た. $\mathrm{BaTiO}_{3}$ にこの焼結助剤を添加しマイクロ波焼成した時の 焼結挙動, およびその焼結体の電気的特性への影響について 検討を行った.

\section{2 実験方法}

出発原料として, $\mathrm{BaTiO}_{3}$ 粉末 (堺化学工業(株) BT-01 粉末, 
平均粒子径 $0.1 \mu \mathrm{m}$ ), $\mathrm{BaCO}_{3}$ 粉末 (和光純薬工業(侏), $\mathrm{H}_{3} \mathrm{BO}_{3}$ 粉 末(関東化学(侏) を使用した. Table 1 に仕込子組成を示す。試 料 $\mathrm{A}$ は無添加の $\mathrm{BaTiO}_{3}$ であり, $\mathrm{B}$ は $\mathrm{BaTiO}_{3}$ 粉末に焼結助剤 として $\mathrm{BaCO}_{3}$ 粉末, $\mathrm{H}_{3} \mathrm{BO}_{3}$ 粉末を添加した試料, $\mathrm{C}$ は $\mathrm{BaTiO}_{3}$ 粉末に予め合成した $\mathrm{BaB}_{2} \mathrm{O}_{4}$ 粉末を添加した試料である. $\mathrm{BaB}_{2} \mathrm{O}_{4}$ 粉末の合成は所定量の $\mathrm{BaCO}_{3}, \mathrm{H}_{3} \mathrm{BO}_{3}$ 粉末を混合した 後, 電気炉により $1120^{\circ} \mathrm{Cで} 30$ 分間焼成し作製した. 所定量に 秤量したそれぞれの粉末を, エタノールを溶媒として混合を 行った．次に，十分乾燥させた混合粉末を $18 \mathrm{~mm} \phi$ の円筒状 ダイスを用いてプレス成形を行い, CIP (冷間等方圧プレス)を 用いて $98 \mathrm{MPa}$ の圧力を負荷し成形体を作製した.この成形体を 炭化ケイ素板 $(20 \mathrm{~mm} \times 20 \mathrm{~mm}$, 厚さ $5 \mathrm{~mm})$ で挟み, ウール状の 断熱用アルミナファイバーに包んでアルミナ坩堝に入れ, 2.45 $\mathrm{GHz}$ のマイクロ波装置(三洋電機, EM-1605)の中に配置した.

マイクロ波の焼成条件は $160 \mathrm{~W}$ で 10 分間加熱の後 $320 \mathrm{~W}$ 5 分から 30 分間加熱した. この時, 試料と炭化ケイ素板との 反応を抑えるため, 成形体をアルミナのセッターで挟んだ. 炭化ケイ素板は相対密度が $98.2 \%$ のもを使用した. マイク ロ波で焼成した試料との比較のため, 電気炉による焼成も 行った。焼成条件は昇温速度 $10^{\circ} \mathrm{C} \cdot \mathrm{min}^{-1}$ で, 焼成温度は $\mathrm{A} は$ $1240^{\circ} \mathrm{C} ， 2$ 時間, $\mathrm{B}, \mathrm{C}$ は $1100-1150^{\circ} \mathrm{C}, 2$ 時間とした。得られ た焼結体の密度はアルキメデス法で算出し, 微構造は走査型 電子顕微鏡 $(S E M)$ により観察した. 結晶相の同定は粉末 $X$ 線 回折装置 $(X R D)$ を用いて行った。電気特性測定用試料は約 $1 \mathrm{~mm}$ の厚さに研削し表面に電極を焼きつけた後, 誘電率につ いては $300^{\circ} \mathrm{C} \sim$ 室温の範囲で測定した. 比抵抗の測定は二端 子法により室温にて测定した。また，作製した試料のコンデ

Table 1 Chemical composition of the samples designed in this study.

\begin{tabular}{ll}
\hline Sample & Composition [mol] \\
\hline A & $\mathrm{BaTiO}_{3}$ \\
$\mathrm{~B}$ & $0.985 \mathrm{BaTiO}_{3}-0.015 \mathrm{BaCO}_{3}-0.03 \mathrm{H}_{3} \mathrm{BO}_{3}$ \\
$\mathrm{C}$ & $0.985 \mathrm{BaTiO}_{3}-0.015 \mathrm{BaB}_{2} \mathrm{O}_{4}$ \\
\hline
\end{tabular}

ンサーとしてのライフテストは, 印加電圧 $\mathrm{AC} \pm 1 \mathrm{~V}$, 環境温 度 $85^{\circ} \mathrm{C}$, 周波数 $10 \mathrm{kHz}$ の条件下で行った。

\section{3 実験結果および考察}

3.1 マイクロ波焼成による緻密化

Table 2にマイクロ波と通常の電気炉で焼成した試料の焼成 条件とその相対密度を示す. この表記方法については, Table 1 の仕込み組成 A-C と焼成法 (MW: マイクロ波焼成, CV: 電気 炉焼成)を組み合わせて表記した。試料を緻密化させる条件 として電気炉を用いた場合, 無添加では $1240^{\circ} \mathrm{C}, 2$ 時間の焼 成が必要であった. また, 液相成分として $\mathrm{BaCO}_{3}+2 \mathrm{H}_{3} \mathrm{BO}_{3}$, $\mathrm{BaB}_{2} \mathrm{O}_{4}$ を添加したB_CV, C_CVの試料では, $1100-1150{ }^{\circ} \mathrm{C}, 2$ 時間で緻密化した。一方, マイクロ波を用いた場合は, 無添 加の試料A_MWでは $800 \mathrm{~W}, 30$ 分 $+960 \mathrm{~W}, 10$ 分の焼成が必 要であった. しかし液相成分を添加した試料 B_MW, C_MW では, $160 \mathrm{~W}, 10$ 分 $+320 \mathrm{~W}, 20$ 分の条件で緻密な焼結体が 得られた.これらの結果から, $\mathrm{BaCO}_{3}+2 \mathrm{H}_{3} \mathrm{BO}_{3}, \mathrm{BaB}_{2} \mathrm{O}_{4}$ の液 相成分の添加によって, $\mathrm{BaTiO}_{3}$ を緻密化させる際に必要なマ イクロ波投入エネルギーを低下できることが分かった.

次に, 焼結挙動における液相の影響について調べた。 Bの 組成の試料に対しマイクロ波で予め $160 \mathrm{~W}, 10$ 分加熱後, 320 Wで 5-30 分間マイクロ波照射したときの相対密度の変化を Fig.1に示す. 5 分間照射の場合には，相対密度が $77.0 \%$ 以下 であったが, 10 分で $93.9 \%, 20-30$ 分で $94.0 \%$ に達した. こ の結果から, $320 \mathrm{~W}$ の加熱時間が 5 分から 10 分の間で急激な 緻密化が起こっていることが分かる. Fig. 2 は $320 \mathrm{~W}$ の照射時 間 ((a): $5 \mathrm{~min}$, (b): $10 \mathrm{~min}$, (c): $20 \mathrm{~min},(\mathrm{~d}): 30 \mathrm{~min}$ ) に対する焼結 体の微構造をSEMにより観察した写真である. $320 \mathrm{~W}$ で 5 分 間では微細な粒子のみが観察され粒成長は起こっていなかっ た. 照射時間が 10 分になると粒子は大きく成長した，20-30 分では緩やかな粒成長が認められた．このことから緻密化開 始と同時に粒成長が起こっていることが分かった。

ここで，XRDによって同定した試料の構成相を Fig.3に示 す. $320 \mathrm{~W}$ で 5 分照射の場合には, 主に $\mathrm{BaTiO}_{3}$ (ペロフスカ イト)と $\mathrm{BaCO}_{3}$ であった. 10 分以降では, $\mathrm{BaCO}_{3}$ の減少と,

Table 2 The relative densities and resistivities of resulting $\mathrm{BaTiO}_{3}$ ceramics with different additives and different firing conditions.

\begin{tabular}{llccl}
\hline Sample & Firing conditions & $\begin{array}{c}\text { Relative } \\
\text { Density }\end{array}$ & Resistivity & Property \\
\hline A_MW & $(\mathrm{MW}) 800 \mathrm{~W}-30 \mathrm{~min}+960 \mathrm{~W}-10 \mathrm{~min}$ & $96 \%$ & $>10^{7}$ & Dielectric \\
A_MW_low & $(\mathrm{MW}) 160 \mathrm{~W}-10 \mathrm{~min}+320 \mathrm{~W}-20 \mathrm{~min}$ & $<54 \%$ & - & - \\
B_MW & $(\mathrm{MW}) 160 \mathrm{~W}-10 \mathrm{~min}+320 \mathrm{~W}-20 \mathrm{~min}$ & $94 \%$ & $>10^{7}$ & Dielectric \\
C_MW & $(\mathrm{MW}) 160 \mathrm{~W}-10 \mathrm{~min}+320 \mathrm{~W}-20 \mathrm{~min}$ & $94 \%$ & $10^{4}$ & Semiconductor \\
A_CV & $\left(\right.$ Conv) $1240^{\circ} \mathrm{C}-120 \mathrm{~min}$ & $97 \%$ & $>10^{7}$ & Dielectric \\
B_CV & $\left(\right.$ Conv) $1150^{\circ} \mathrm{C}-120 \mathrm{~min}$ & $94 \%$ & $10^{4}$ & Semiconductor \\
C_CV & (Conv) $1100^{\circ} \mathrm{C}-120 \mathrm{~min}$ & $97 \%$ & $10^{5-6}$ & Semiconductor \\
\hline
\end{tabular}




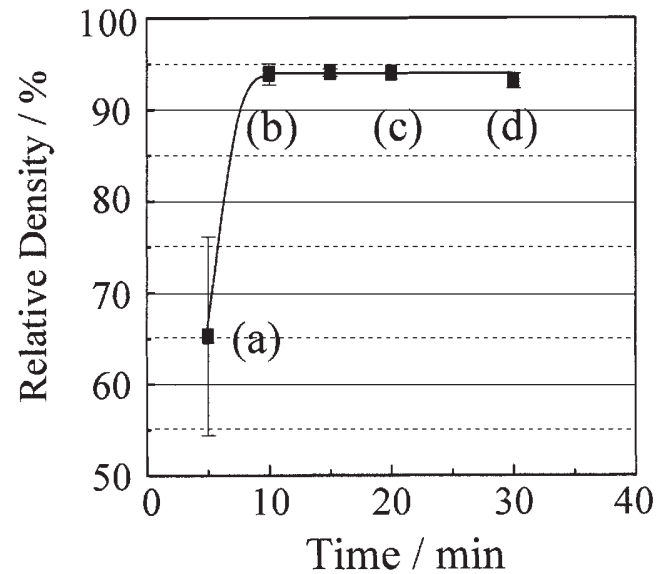

Fig.1 Relative densities of Sample B sintered with various microwave irradiation time. 間に液相成分としての $\mathrm{BaB}_{2} \mathrm{O}_{4}$ が生成され焼結举動に影響を与 えていると考えられる.この液相生成過程を調べるために, DTA (示差熱分析) の測定 (昇温速度 : $10^{\circ} \mathrm{C} \cdot \mathrm{min}^{-1}$, 測定温度 : 室温〜 $\left.1200^{\circ} \mathrm{C}\right)$ を行った. 吸熱ピークが顕著に現れる様に, 助 剤量を $10 \mathrm{~mol} \%$ とし実験を試みた. $\mathrm{BaCO}_{3}+2 \mathrm{H}_{3} \mathrm{BO}_{3}$ 添加にお いて, 吸熱ピークが $630^{\circ} \mathrm{C}$ 付近て観測された(Fig.4). そこで, このピークの現れる前後の相を同定するため $550^{\circ} \mathrm{C}$ と $700^{\circ} \mathrm{C}$ でそれぞれ焼成した試料をXRDにより測定した. $550^{\circ} \mathrm{C} て ゙$ 焼 成した試料の主な構成相は $\mathrm{BaTiO}_{3}$ と $\mathrm{BaCO}_{3}$ であった.一方, $700^{\circ} \mathrm{C}$ で焼成した試料は $\mathrm{BaCO}_{3}$ が消光 $\mathrm{BaB}_{2} \mathrm{O}_{4}$ が観測された。 したがって, $\mathrm{B}$ の試料では $630^{\circ} \mathrm{C}$ 付近で $\mathrm{BaCO}_{3}$ と $\mathrm{H}_{3} \mathrm{BO}_{3}$ が反
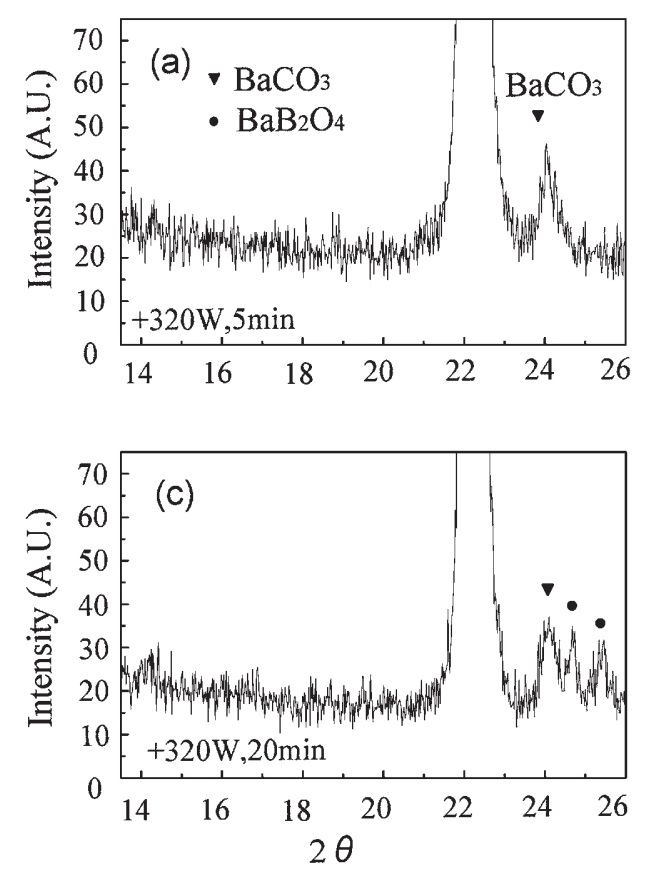

$\mathrm{BaB}_{2} \mathrm{O}_{4}$ が新たに見られた. 従って, $320 \mathrm{~W}$ で5分から 10 分の
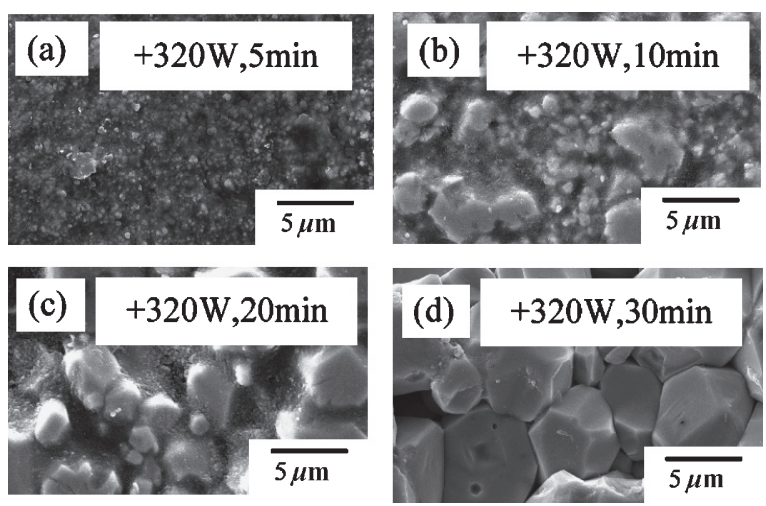

Fig.2 Microstructure of each irradiation time of the Sample B: (a) $160 \mathrm{~W}, 10 \mathrm{~min}+320 \mathrm{~W}, 5 \mathrm{~min}$, (b) $160 \mathrm{~W}, 10 \mathrm{~min}+320$ $\mathrm{W}, 10 \mathrm{~min}$, (c) $160 \mathrm{~W}, 10 \mathrm{~min}+320 \mathrm{~W}, 20 \mathrm{~min}$, (d) $160 \mathrm{~W}$, $10 \mathrm{~min}+320 \mathrm{~W}, 30 \mathrm{~min}$.

応し $\mathrm{BaB}_{2} \mathrm{O}_{4}$ が生成していることがわかった.この結果から, 液相として $\mathrm{BaB}_{2} \mathrm{O}_{4}$ が存在することによってマイクロ波加熱を 利用した液相焼結が起こり, 焼結が促進されて緻密化したと 推察される.ここで, $320 \mathrm{~W}, 10$ 分以降のXRDの結果に見ら れる $\mathrm{BaCO}_{3}$ については, $\mathrm{BaCO}_{3}$ と $\mathrm{H}_{3} \mathrm{BO}_{3}$ の反応が十分に進行 しなかったための残留物質と考えられる.

3.2 焼結体の電気的特性

焼成法の違いが電気的特性に及ぼす影響について検討を 行った. Table 2 に室温における各試料の比抵抗を示す. 無添 加の試料 A では電気炉およびマイクロ波焼成に関らず $10^{7}$ $[\Omega \cdot \mathrm{m}]$ 以上であり誘電体特性を示した. 一方, $\mathrm{BaB}_{2} \mathrm{O}_{4}$ 添加の 試料 Cではいずれの焼成方法でも $10^{4-5}[\Omega \cdot \mathrm{m}]$ で半導体特性
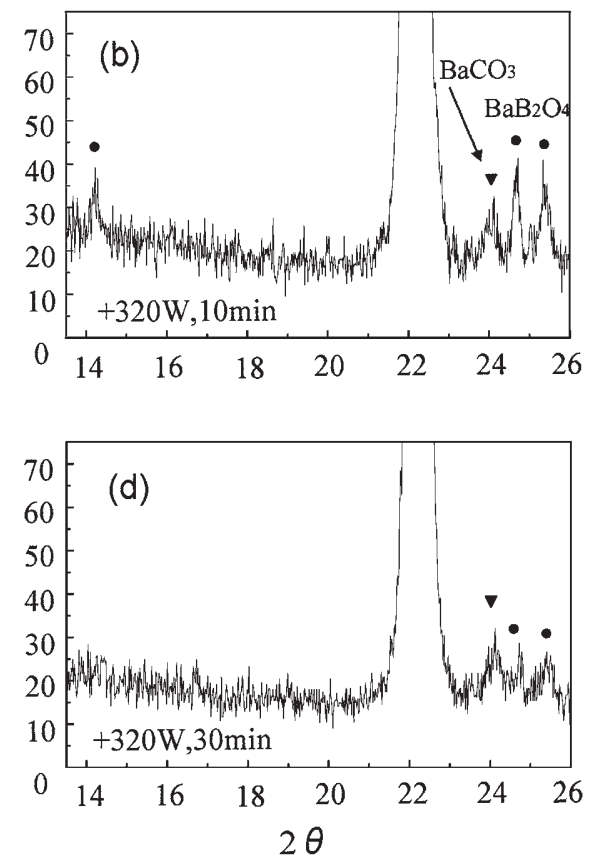

Fig.3 XRD patterns of the sample B: (a) $160 \mathrm{~W}, 10 \mathrm{~min}+320 \mathrm{~W}, 5 \mathrm{~min}$, (b) $160 \mathrm{~W}, 10 \mathrm{~min}+320 \mathrm{~W}, 10 \mathrm{~min}$, (c) $160 \mathrm{~W}, 10 \mathrm{~min}+320 \mathrm{~W}, 20$ $\mathrm{min}$, (d) $160 \mathrm{~W}, 10 \mathrm{~min}+320 \mathrm{~W}, 30 \mathrm{~min}$. 


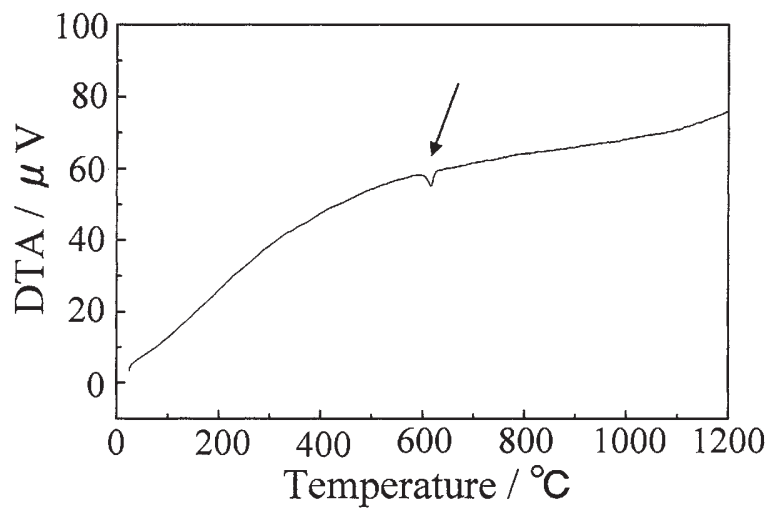

Fig.4 DTA curves of $\mathrm{BaTiO}_{3}$ ceramics with different additives. Composition: $0.9 \mathrm{BaTiO}_{3}-0.1 \mathrm{BaCO}_{3}-0.2 \mathrm{H}_{3} \mathrm{BO}_{3}$

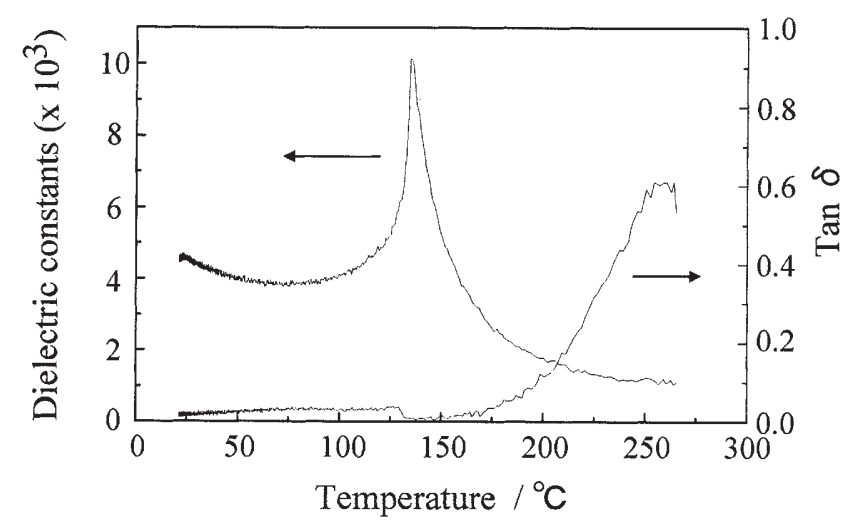

Fig.5 Temperature dependence of dielectric constant (Sample B_MW).

であった. ところが, $\mathrm{BaCO}_{3}+2 \mathrm{H}_{3} \mathrm{BO}_{3}$ として添加した試料 $\mathrm{B}$ では，マイクロ波焼成では $10^{7}[\Omega \cdot \mathrm{m}]$ 以上であり誘電体特性 を示したのに対し，電気炉焼成では $10^{4}[\Omega \cdot \mathrm{m}]$ で半導体特性 を示した. つまり, マイクロ波焼成と電気炉焼成の間で相違 があった．そこで，誘電体特性を示した B_MW の試料の $\mathrm{BaTiO}_{3}$ 特性を確かめるために, 誘電特性について測定を行っ た. Fig. 5 はその測定結果である. $120^{\circ} \mathrm{C}$ 付近にキュリー点 $\left(\mathrm{T}_{\mathrm{c}}\right)$ が見られる典型的な $\mathrm{BaTiO}_{3}$ の誘電特性が確認され, 無添加の 試料と同じ傾向であった. 従って, 低出力のマイクロ波焼成 において液相成分として $\mathrm{BaCO}_{3}+2 \mathrm{H}_{3} \mathrm{BO}_{3}$ を添加する場合に は, 本来の $\mathrm{BaTiO}_{3}$ の持つ誘電特性を損なうことなく焼結が可 能であるといえる.さらに，その焼結体の信頼性を確認する ために, ライフテストを行った. Fig.6は静電容量の経時変化 を測定した結果である. 両者の試料において, 初期減衰の後 は長期に亘って安定して㧍り指数関数的減衰挙動であった. また, その滅衰率を比較してもマイクロ波焼成の方が滅衰率 が小さいことがわかる.このことから，マイクロ波で焼成し た試料に㧍いても電気炬により作製した試料と同等もしくは それ以上のライフパフォーマンスを有しているということが 確認できた.

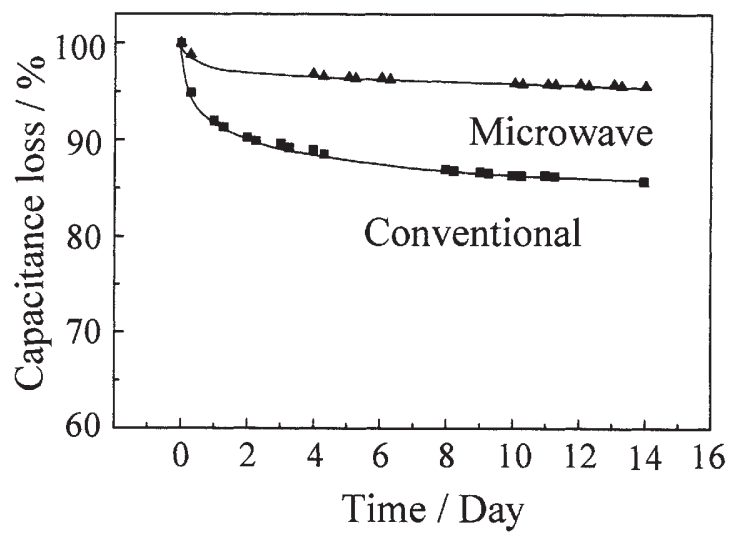

Fig.6 The capacitance loss of the $\mathrm{BaTiO}_{3}$ ceramics at $1 \mathrm{~V}, 85^{\circ} \mathrm{C}$ and $1 \mathrm{kHz}$.

$\mathrm{BaTiO}_{3}$ の助剤添加における半導体化については, 価数の異 なる原子の置換固溶によるという考え方に加え, 格子サイト 間の空隙に添加原子が入る場合 ${ }^{7.8)}$ や粒界に元素が偏析するこ とによる場合”などが考えられている，従って，電気炉を用 いて作製した焼結体では反応時間が長く液相成分が十分に生 成されたため, 液相成分とマトリックス相の間で相互拡散が 進行し, 固溶もしくはその他の原子の移動などによりバンド 構造にドナー準位もしくはアクセプター準位を形成し半導体 化したと考えられる. 一方, マイクロ波焼成では絶縁体であ り前述のような拡散が起こらなかったと考えられる.つまり, マイクロ波と電気炉焼成では液相内での拡散反応が異なるこ とを示している.この物質拡散の差については, マイクロ波 を用いて選択加熱が起こった場合に, 局所的に大きな温度勾 配が存在することによって熱流束の方向に一方的な物質拡散 が起こると考えられている ${ }^{10}$. この一方向の拡散の発現につ いては, 誘電損失の異なる粒子を用いた合成の際の粒子の形 状・サイズ等の振る舞いを詳しく観察することでも検討でき るとされており，2.45 GHzのマイクロ波照射下で選択加熱が 生じた場合の熱的非平衡による固相反応の解釈に慗がるとし て, 今後更なる研究が必要であると思われる.

\section{4 結 言}

マイクロ波焼成により $\mathrm{BaTiO}_{3}$ を液相焼結し，その時の焼結 挙動, 焼結体の電気的特性への影響について調查し, 以下の 結果が得られた.

(1) 液相成分の添加により，マイクロ波焼成において非常に 低出力短時間で, 電気炉焼成により得られた試料と同程 度の相対密度の焼結体が得られた.このことから, $\mathrm{BaTiO}_{3}$ 焼結体の緻密化およびマイクロ波による低出力焼成には, 液相成分の添加が大きく寄与することが分かった.

(2) マイクロ波焼成によって, $\mathrm{BaCO}_{3}$ と $\mathrm{H}_{3} \mathrm{BO}_{3}$ を液相成分と して添加した試料では, 通常の電気炕焼成と異なる焼成 過程であるため, $\mathrm{BaTiO}_{3}$ 本来の誘電特性を保持した焼結 体を作製することが可能であった. 
謝辞

本研究の遂行にあたり, 楠本慶二博士, 中村和雄氏, 白井 孝博士(独立行政法人・産業技術総合研究所)に多くの助言や 技術的サポートを頂きましたことに対し，深く感謝致します。

\section{文献}

1) D.M.P.Mingos and D.R.Baghurst: "Applications of Microwave dielectric Heating Effects to Synthetic Problems in Chemistry", Chem. Soc. Rev., 20(1991)1-47.

2) W.H.Sutton: "Microwave Processing of Ceramic Materials", Am. Ceram. Soc. Bull., 68(1989)376-386.

3) M.A.Janney and H.D.Kimrey: "Diffusion-Controlled Processes in Microwave-Fired Oxide Ceramics", Microwave Processing of Materials II, ed. by W. B. Snyder et al., Meter. Res. Soc. Proc., 189(1991)215-227.

4) H.D.Kimrey, J.O.Kiggans, M.A.Janney and R.L.Beatty: "Microwave Sintering of Zirconia-Toughened Alumina
Composites", Microwave Processing of Materials II, ed. by W. B. Snyder et al., Meter. Res. Soc. Proc., 189(1991)243-255.

5) T.N.Tiegs, J.O.Kiggans and H.D.Kimrey: "Microwave Sintering of Silicon Nitride", Ceram. Eng. Sci. Proc., 12(1991)1981-1992.

6) Y.Goto and L.E.Cross: "Phase Diagram of the $\mathrm{BaTiO}_{3}-\mathrm{BaB}_{2} \mathrm{O}_{4}$ System and Growth of $\mathrm{BaTiO}_{3}$ Crystals in the Melt", YogyoKyokai-Shi, 77(11)(1969)355-357.

7) H.M.Chan, M.P.Harmer and D.M.Smyth: "Compensating Defects in Highly Donor-Doped $\mathrm{BaTiO}_{3}$ ", J. Am. Ceram. Soc., 69(1986)507.

8) J.Daniels and R.Wernicke: "Part V. New Aspects of an Improved PTC model", Philips Res. Rep., 31(1976)544-59.

9) W.Heywang: "Semiconducting Barium Titanate", J.Mater. Sci., 6(1971)1214-1220.

10) H.Takizawa and T.Kimura: "Synthesis of Inorganic Materials by Millimeter-Wave Irradiation", Kouon-Gakkai-Shi, 29(1)( 2003)26-32. 